\title{
Haploinsufficiency and Reduced Expression of Genes Localized to the 8p Chromosomal Region in Human Prostate Tumors
}

\author{
Hassan Chaib,' James W. MacDonald, ${ }^{2}$ Robert L. Vessella, ${ }^{3}$ Joseph G. Washburn, ${ }^{2}$ Janna E. Quinn, ${ }^{3}$ \\ Austin Odman, ${ }^{3}$ Mark A. Rubin, ${ }^{1,4}$ and Jill A. Macoska ${ }^{1,2 *}$ \\ 'Department of Urology, The University of Michigan, Ann Arbor, Michigan \\ ${ }^{2}$ The Comprehensive Cancer Center cDNA and Affymetrix Microarray Core, The University of Michigan, Ann Arbor, Michigan \\ ${ }^{3}$ Department of Urology, The University of Washington, Seattle, Washington \\ ${ }^{4}$ Department of Pathology, The University of Michigan, Ann Arbor, Michigan
}

\begin{abstract}
Cytogenetic and molecular studies have suggested that deletion or rearrangement of sequences that map to the short arm of chromosome 8 may be permissive for tumorigenesis in several organ systems, and in human prostate tumors in particular. In this study, we hypothesized that genes deleted for one copy and localized to the 8p chromosomal region may be transcriptionally down-regulated or ablated in affected human prostate tumor tissues. To test this hypothesis, we used cDNA microarray analysis to determine the transcriptional profiles for 259 transcribed sequences mapping to the 8p chromosomal region for seven human prostate tumor xenografts, completely characterized for numerical and structural alterations on chromosome 8, and five normal human prostate tissues. These experiments identified 33 genes differentially expressed between normal and malignant prostate tissues, the majority of which $(28 / 33,85 \%)$ were transcriptionally down-regulated in malignant compared to normal human prostate tissues. These findings, that haploinsufficiency and transcriptional downregulation for genes mapping to 8p are largely coincident in human prostate tumors, should provide a powerful tool for the identification of tumor-suppressor genes associated with human prostate cancer initiation and progression.
\end{abstract}

(c) 2003 Wiley-Liss, Inc.

\section{INTRODUCTION}

Cytogenetic and molecular studies have suggested that deletion or rearrangement of sequences that map to the short arm of chromosome 8 may be permissive for tumorigenesis in several organ systems. In prostate carcinoma, early work by Bergerheim et al. (1993) by the use of Southern blot techniques showed high frequencies of deletion of distal $8 \mathrm{p}$ sequences in human prostate tumors, and suggested that a breakpoint existed between the NEFL locus at $8 \mathrm{p} 21$ and the PLAT locus at $8 \mathrm{p} 21-$ $8 \mathrm{p} 11$. Subsequent work in our laboratory identified a major region of deletion mapping to $8 \mathrm{p} 22$ in human prostate cancer (Macoska et al., 1995). This was corroborated by the description and later characterization of a homozygous deletion within the 8p22-p23 region in a prostate tumor (Bova et al., 1993, 1996). The use of polymerase chain reaction (PCR) and fluorescence in situ hybridization (FISH) techniques in our laboratory and by others confirmed frequent loss of distal $8 \mathrm{p}$ sequences and showed that this region of deletion could be quite extensive, including the entire $8 \mathrm{p}$ chromosome arm or large portions of $8 \mathrm{p}$ extending from $8 \mathrm{pter}$ to 8p11-12 (MacGrogan et al., 1994; Macoska et al.,
1994; Trapman et al., 1994; Prasad et al., 1998). Two large studies from our laboratory showed interstitial deletions of distal sequences mapping to $8 \mathrm{p} 22,8 \mathrm{p} 21$, and 8p11-p12, including homozygous deletion of sequences mapping to the $D 8 S 87$ locus at 8 p12, in human prostate tumors (Macoska et al., 1995; Prasad et al., 1998). As a result of these studies, we and others have hypothesized that one or more tumor-suppressor genes critical for prostate tumorigenesis map to $8 \mathrm{p}$.

It is reasonable to propose that the transcription of genes mapping to chromosomal regions deleted

M. Rubin is currently at Department of Pathology, Brigham and Women's Hospital, Boston, MA.

Supported by: National Cancer Institute; Grant numbers: 5 R01 CA60948 and 5 P30 CA46592; George M. O'Brien Prostate Cancer Research Center of the University of Washington Department of Urology; Grant number: 5 P50 DK47656; Department of Veterans Affairs.

* Correspondence to: Dr. Jill A. Macoska, Department of Urology, The University of Michigan, 7306 CCGC, 1500 East Medical Center Drive, Ann Arbor, MI 48109-0946.

E-mail: jcoska@umich.edu

Received 20 December 2002; Accepted 12 February 2003

DOI 10.1002/gcc.10226 
for one or both copies may be down-regulated or ablated in the affected tumor tissues. If so, then deletion-induced haploinsufficiency alone may result in reduced or ablated gene transcription in affected tumor tissues. To test this hypothesis, we determined the RNA profiles of seven human prostate tumor xenografts, completely characterized for numerical and structural alterations on chromosome 8 , and five normal human prostate tissues for 677 transcribed sequences mapping to chromosome 8 , by use of cDNA microarray analysis. These experiments demonstrate the down-regulation or ablation of transcripts from 28 genes mapping to regions of $8 \mathrm{p}$ deleted in the prostate tumor xenografts and are consistent with the identification of these sequences as candidate tumor-suppressor genes that are inactivated during prostate tumorigenesis.

\section{MATERIALS AND METHODS}

\section{Tissue Acquisition and Characterization}

Normal benign human prostate tissue was obtained after radical prostatectomy from patients diagnosed with prostate cancer. After an initial pathologic evaluation of radical prostatectomy tissue, presumed normal tissue was snap-frozen in liquid nitrogen and stored at $-70^{\circ} \mathrm{C}$. One section from each specimen was examined after staining with H\&E, and the specimen was included in the study if the section demonstrated at least $70 \%$ epithelial cells. All radical prostatectomy specimens were acquired with full Institutional Review Board approval. The LuCaP series of human prostate tumor xenografts was chosen for these studies because it constitutes a renewable, largely characterized source of human prostate tumor tissue (Ellis et al., 1996; Williams et al., 1997; Linja et al., 2001; Corey et al., 2002; Laitinen et al., 2002; True et al., 2002). The xenografts were maintained by serial passage in intact athymic Balbc nu/nu male mice and were harvested at passage 45 for LuCaP 23.1, 40 for LuCaP 23.8, 25 for LuCap 23.12, 67 for LuCaP 35, 17 for LuCaP 41, 22 for LuCaP 49, and 19 for LuCaP 58. At sacrifice, tumor samples were harvested and frozen in optimum cutting temperature medium.

\section{Alleleotyping}

PCR was used for amplification of sequences containing highly polymorphic microsatellite repeat markers at loci of interest on chromosome 8 (12 sequences). The cytogenetic and map position for each locus was obtained from the UCSC Ge- nome Bioinformatics database (http://genome.cse. ucsc.edu/). Primer sequences were obtained from public databases maintained by the National Center for Biotechnology Information (http://www. ncbi.nlm.nih.gov/), as accessed through the Internet. DNA was prepared from frozen xenograft tissues, and PCR reactions were performed as previously described (Prasad et al., 1998). Allelic dosage was scored as " 1 " if a single band was observed in the PCR reaction or as " 2 " if two discrete bands were observed.

\section{RNA Profiling by cDNA Microarray}

RNA was prepared from normal benign prostatic and xenograft tissues after homogenization and lysis in Trizol reagent (Invitrogen Life Technologies, Carlsbad, CA) following the manufacturer's instructions. The RNA was further purified by use of RNeasy reagents (Qiagen, Valencia, CA), and 20 $\mu \mathrm{g}$ of total RNA from each sample was labeled with Cy5 fluorescent dye by use of a CyScribe firststrand cDNA labeling kit. For each experiment, 20 $\mu \mathrm{g}$ of Universal Human Reference RNA (Stratagene, La Jolla, CA) was labeled with Cy3 by use of similar protocols. After purification on AutoSeq G50 columns (Amersham Biosciences, Piscataway, $\mathrm{NJ}$ ), the labeled probes were combined, dried down to $5 \mu \mathrm{l}$, and added to $45 \mu \mathrm{l}$ SlideHyb \#1 hybridization buffer (Ambion, Houston, TX), prewarmed to $68^{\circ} \mathrm{C}$. The probe/hybridization mixture was pre-incubated at $68^{\circ} \mathrm{C}$ for $5 \mathrm{~min}$, then transferred to the cDNA microarray slide, which was coverslipped and incubated in a moist chamber at $45^{\circ} \mathrm{C}$ for $16 \mathrm{hr}$. The slides were washed for $10 \mathrm{~min}$ each in $2 \times \mathrm{SSC}, 0.2 \% \mathrm{SDS}$ at $45^{\circ} \mathrm{C}, 2 \times \mathrm{SSC}$ at room temperature, and $0.2 \times \mathrm{SSC}$ at room temperature; rinsed; dried; and evaluated with a GenePix 4000A Axon laser scanner and associated software (Axon Instruments, Burlingame, CA).

\section{Chromosome 8 cDNA Array}

The custom chromosome 8 array was produced at the University of Michigan Comprehensive Cancer Center cDNA and Affymetrix Microarray Core. This array consisted of PCR products amplified from 677 Research Genetics (Huntsville, AL) human cDNA clones whose sequences mapped to chromosome 8. To identify these clones, our laboratory annotated the GenBank accession numbers associated with all 25,921 Research Genetics human cDNA clones with chromosomal location by use of information from the National Center for Biotechnology Information Ensembl database (http://www.ensembl.org/homo_sapiens) and the 
UCSC Genome Bioinformatics database (http:// genome.cse.ucsc.edu/). According to information in these databases, 677 clones contained sequences mapping to human chromosome 8; 259 mapped to $8 p$ and 418 mapped to 8q. A complete list of cDNAs spotted onto the chromosome 8 array can be obtained at http://www-personal.umich.edu/ $\sim$ jcoska/Chrom8Array.xls.

\section{Northern Blot Analysis}

A 20- $\mu \mathrm{g}$ sample of total RNA from each specimen isolated as described above was resolved on $1 \%$ formaldehyde agarose gels and transferred to a Nytran membrane by use of a TurboBlotter apparatus (Schleicher \& Schuell, Keene, NH). Each blot was probed with radiolabeled PCR products amplified for the gene of interest, hybridized by use of the ExpressHyb Hybridization Solution (Clontech, Palo Alto, CA), and visualized on XOMAT film (Kodak, Rochester, NY).

\section{Statistical Analysis}

Data used for this study were background-subtracted median intensity values with average $\log$ intensities greater than 8. Data from each array were normalized to remove dye-bias by use of a rank-invariant normalization method (Tseng et al., 2001). This normalization method attempts to find genes that do not appear to be differentially expressed in the two samples hybridized to a microarray. A non-linear regression (lowess) line was then fitted to these points and used for normalizing the data. Before making comparisons between arrays, we performed a quantile normalization of the rankinvariant normalized array data. We assumed that the distribution of the array data was the same for all arrays, but that the scale of the data may be quite different. To correct for this difference in scale, we used data from one array as baseline and adjusted all other arrays to match (Shedden, 2002a,b). Differentially expressed genes were detected with SAM (significance analysis of microarrays) (Tusher et al., 2001). Hierarchical clustering was used for grouping of genes with similar expression patterns (Eisen et al., 1998).

\section{RESULTS}

\section{Allelotyping}

Allelotyping experiments showed that LuCaPs 23.1, 49, and 58 demonstrated one allele for all twelve $8 \mathrm{p}$ loci examined, suggesting that one copy of the entire short arm of chromosome 8 was deleted in those specimens. LuCaP 23.8 also demon- strated extensive deletion for one copy of $8 \mathrm{p}$, although the results were inconclusive for the most proximal locus, D8S255, thus precluding an assessment of complete deletion. LuCaP 23.12 demonstrated one allele for 10 loci extending from D8S504 to D8S87 and two alleles at locus D8S1121, suggesting that the most proximal portion of $8 \mathrm{p}$ was retained in that xenograft. LuCaPs 35 (loci D8S504-NEFL) and 41 (loci D8S504-D8S540) demonstrated deletion for one copy of distal $8 \mathrm{p}$ with retention of two copies of proximal $8 \mathrm{p}$ sequences (Table 1). Taken together, the allelotyping data demonstrated deletion for one copy of the entire $8 p$ chromosomal region for all xenografts except LuCaPs 35 and 41, which were deleted for one copy of the distal $8 p$ region only. These results were consistent with those obtained by others who used FISH and comparative genome hybridization (CGH), except that LuCaP 35 evinced loss of distal $8 \mathrm{p}$ by allelotyping but not by $\mathrm{CGH}$ analysis, and LuCaP 41 demonstrated loss of all of one copy of the entire $8 \mathrm{p}$ arm by CGH analysis but not by allelotyping (Williams et al., 1997; Laitinen et al., 2002). In addition, FISH and CGH analyses demonstrated gain of one copy of 8q in LuCaPs 23.8, 23.12, 35, and 58, and amplification of 8cen-q21 and 8q24-qter in LuCap 23.8, 8q21-q22 in LuCaP 35, and 8q23-qter in LuCaP 58 (Williams et al., 1997; Laitinen et al., 2002).

\section{cDNA Microarray Analysis}

The xenograft tissues were transcriptionally profiled for coding sequences mapping to chromosome 8. To accomplish this, we constructed a chromosome 8 array by use of PCR products amplified from 677 clones from the Research Genetics human cDNA library whose sequences mapped to chromosome 8 . The chromosome 8 sequence specificity and the exact physical location of each transcript on chromosome 8 were established by annotation of the cloned sequences with chromosome mapping information derived from the National Center for Biotechnology Information Ensembl database (http://www.ensembl.org/homo_sapiens) and the UCSC Genome Bioinformatics database (http://genome.cse.ucsc.edu/).

Five specimens of histologically verified normal benign human prostate tissues obtained after radical prostatectomy from patients diagnosed with prostate cancer were used as controls. The five normal benign prostate tissues and LuCaP tumors 23.1, 23.12, 23.8, 35, 41, 49, and 58 were analyzed for the gene expression pattern of tran- 

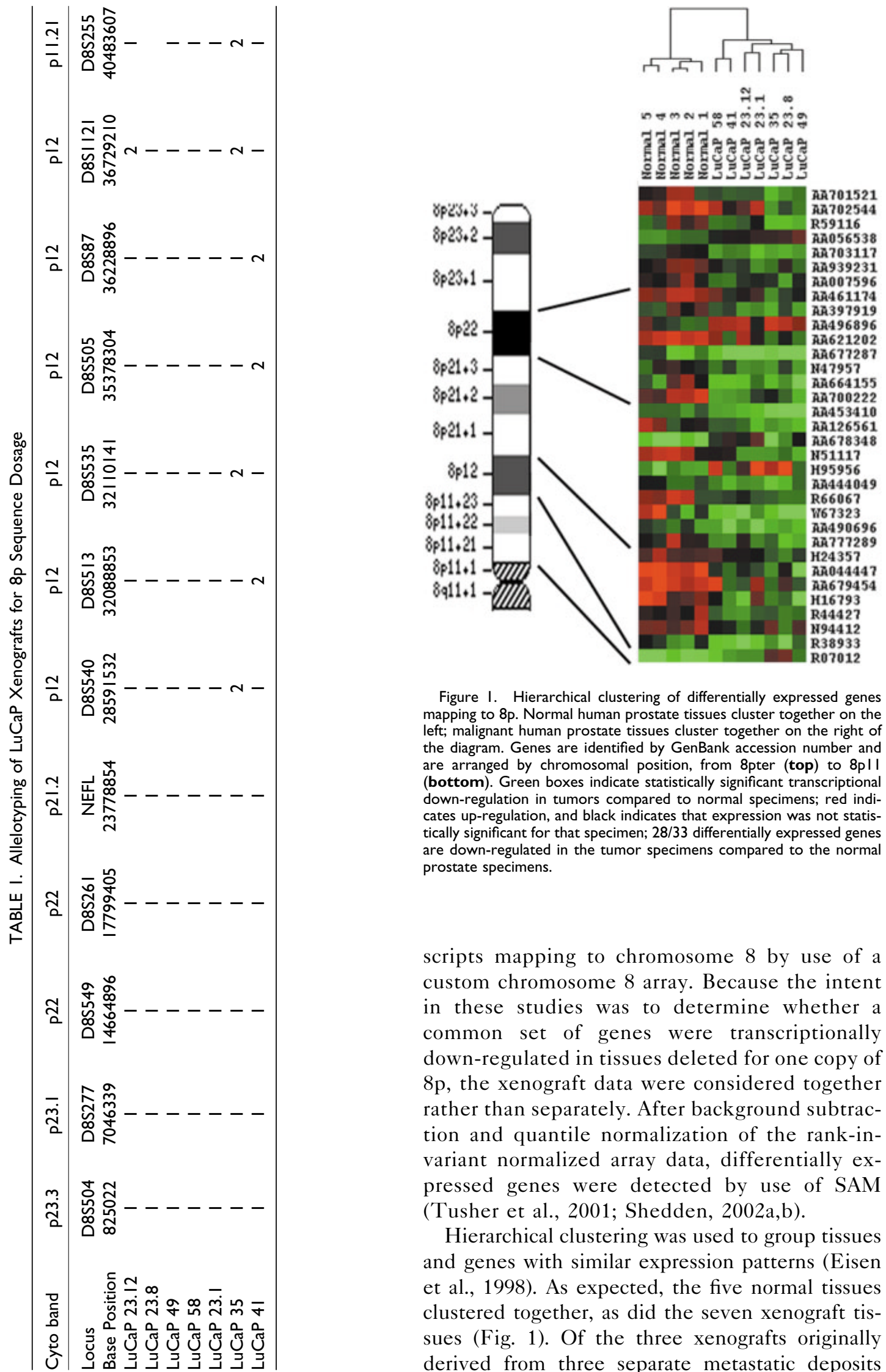

Figure I. Hierarchical clustering of differentially expressed genes mapping to 8p. Normal human prostate tissues cluster together on the left; malignant human prostate tissues cluster together on the right of the diagram. Genes are identified by GenBank accession number and are arranged by chromosomal position, from 8pter (top) to $8 \mathrm{pll}$ (bottom). Green boxes indicate statistically significant transcriptional down-regulation in tumors compared to normal specimens; red indicates up-regulation, and black indicates that expression was not statistically significant for that specimen; $28 / 33$ differentially expressed genes are down-regulated in the tumor specimens compared to the normal prostate specimens.

scripts mapping to chromosome 8 by use of a custom chromosome 8 array. Because the intent in these studies was to determine whether a common set of genes were transcriptionally down-regulated in tissues deleted for one copy of $8 \mathrm{p}$, the xenograft data were considered together rather than separately. After background subtraction and quantile normalization of the rank-invariant normalized array data, differentially expressed genes were detected by use of SAM (Tusher et al., 2001; Shedden, 2002a,b).

Hierarchical clustering was used to group tissues and genes with similar expression patterns (Eisen et al., 1998). As expected, the five normal tissues clustered together, as did the seven xenograft tissues (Fig. 1). Of the three xenografts originally derived from three separate metastatic deposits 
from the same patient (LuCaPs 23.1, 23.8, and 23.12), LuCaPs 23.1 and 23.12 clustered together, whereas LuCaP 23.8 clustered with LuCaP 35. Interestingly, LuCaPs 23.1 and 23.12 were both characterized by gain of the entire $8 \mathrm{q}$ chromosomal arm, whereas LuCaPs 23.8 and 35 were distinguished by gain of $8 \mathrm{q}$ and amplification of discrete regions on 8q (Williams et al., 1997; Laitinen et al., 2002).

Statistical analysis demonstrated that the mean expression of 88/677 (13\%) genes spotted onto the array was statistically significantly different in prostate tumor xenografts compared to normal prostate tissues. Of the 88 differentially expressed genes, 33 mapped to $8 \mathrm{p}$ and 55 to $8 \mathrm{q}$. Twenty-eight of 33 $(85 \%)$ of the differentially expressed genes that mapped to $8 \mathrm{p}$ were down-regulated in the prostate tumor xenografts compared to normal prostate tissues. These results are consistent with the expectation that a majority of genes mapping to $8 \mathrm{p}$ would be transcriptionally down-regulated in the prostate tumor xenografts, which are deleted for one copy of $8 \mathrm{p}$. The five gene sequences that constitute the exceptions to this trend encode two ESTs (GenBank H95956, R07012), two hypothetical proteins (GenBank AA056538, AA678348), and the ATIP1 gene (GenBank AA496896). Interestingly, three genes previously identified as tumor-suppressor genes mapping to 8p (NKX3.1, LZTS1, and MSR1) were transcriptionally down-regulated in a subset of the $8 \mathrm{p}$-deleted xenografts but did not achieve significance by SAM analysis. NKX3.1 was downregulated in LuCaPs 35 and 49, MSR1 was downregulated in LuCaPs 41 and 49, and LZTS1 was down-regulated in LuCaPs 23.1, 23.12, 49, and 58.

The expression pattern on $8 \mathrm{q}$ was more complex, with 23 genes (42\%) up-regulated and 32 genes $(58 \%)$ down-regulated in the prostate tumor xenografts compared to normal prostate tissues. There were no obvious correlations between gene expression level and 8q copy number in the prostate tumor xenografts, although the proportion of up-regulated genes was significantly higher on the $\mathrm{q}$ arm than on the $\mathrm{p}$ arm $(P<0.017)$. The identities of the differentially expressed genes mapping to $8 \mathrm{p}$ are listed in Table 2. The observation of transcriptional down-regulation for the majority of differentially expressed genes mapping to $8 \mathrm{p}$ in the xenografts compared to normal prostate tissues is consistent with the allelotyping data demonstrating loss of all or part of one copy of $8 p$ in the seven xenografts (Table 1 and Fig. 1).

\section{Validation of cDNA Microarray Data}

We conducted Northern blot analysis to determine whether the gene expression profiles acquired from the cDNA microarray data were accurate. Two transcripts originating from genes mapping to the proximal $8 \mathrm{p}$ region were chosen for the validation studies, RBP-MS and TEM5. $R B P-M S$ was chosen in particular because PCR products from two different cDNA clones representing this sequence were spotted onto the array, and expression data acquired from both spots were consistent with transcriptional down-regulation of $R B P-M S$ in the xenografts (Table 2). The same Northern blot filter was sequentially hybridized to radiolabeled probes for $R B P-M S$, TEM5, and $G A P D H$ (as a loading control) and demonstrated expression of all three genes in three of the same normal human prostate tissues previously analyzed by cDNA microarray (N4, N5, and N6) (Fig. 2). However, both RBP-MS and TEM5 were not expressed in LuCaPs 49, 23.1, and 41, whereas $G A P D H$ was abundantly expressed in all three prostate tumor xenograft tissues (Fig. 2). These results were consistent with the cDNA microarray results and demonstrated ablation of TEMS and $R B P-M S$ gene expression in prostate tumor xenografts deleted for one copy of $8 \mathrm{p}$.

\section{DISCUSSION}

These studies were intended to determine whether gene dosage correlated with gene expression level in human prostate tumors with known structural and numerical alterations involving chromosome 8 . The xenograft tissues were particularly suited to these studies because they provided a renewable source of prostate tumor tissue with known 8p deletions that could be extensively characterized by RNA profiling. Prostate cancer cell lines could also have been examined, but proved to be unsuitable because they were far less "uniform" in their chromosome 8 composition, and it was unclear whether some cell lines demonstrated deletion in addition to translocation of $8 p$ sequences. For example, LNCaP cells have four copies of chromosome 8; DU145 exhibits a der(7;8)(p10;q10) translocation; and PC3 exhibits $\operatorname{del}(8) \mathrm{p} 21, \operatorname{der}(8)$ $\mathrm{t}(\mathrm{X} ; 8)(\mathrm{q} 10 ; \mathrm{q} 10)$, and $\operatorname{der}(8) \mathrm{t}(8 ; 15)(\mathrm{q} 10 ; 10)$ chromosomes (Beheshti et al., 2000). The 22Rv1 cell line actually demonstrates gain for a portion of $8 p$, including 8p12-p22 (Laitinen et al., 2002). Therefore, we chose to profile the LuCaP series of human prostate tumor xenografts with known $8 \mathrm{p}$ 
TABLE 2. Differential Expression of 8p Transcripts

\begin{tabular}{|c|c|c|c|c|c|}
\hline Symbol & $\begin{array}{c}\text { GenBank } \\
\text { accession no. }\end{array}$ & $\begin{array}{l}\text { Fold } \\
\text { change }\end{array}$ & $\begin{array}{c}\text { Base } \\
\text { position }\end{array}$ & Trend & $\begin{array}{l}\text { Cyto } \\
\text { band }\end{array}$ \\
\hline ESTs & AA70I52I & -2.488 & 131657 & Down & $8 p 23$ \\
\hline KIAA07II & AA702544 & -1.912 & 1633119 & Down & $8 p 23$ \\
\hline ESTs & R59II6 & -1.948 & 2434358 & Down & $8 p 23$ \\
\hline FLJII210 & AA056538 & 3.402 & 7055704 & $U_{p}$ & $8 p 23$ \\
\hline DKFZp434D2426 & AA703II7 & -3.237 & 9116035 & Down & $8 p 23$ \\
\hline TNKS & AA93923I & -2.135 & 9721956 & Down & $8 p 23$ \\
\hline ESTs & AA007596 & -1.977 & 12496945 & Down & $8 p 23$ \\
\hline ZDHHC2 & AA46II74 & $-2.5 \mathrm{II}$ & $174 \mid 6305$ & Down & $8 p 22$ \\
\hline FLJ32642 & AA397919 & -1.901 & I 7488997 & Down & $8 p 22$ \\
\hline ATIPI & AA496896 & 2.580 & I 7837267 & Up & $8 p 22$ \\
\hline ESTs & AA621202 & -2.644 & 17846673 & Down & $8 p 22$ \\
\hline FGLI & AA677287 & -2.785 & 18045902 & Down & $8 p 22$ \\
\hline PCMI & N47957 & -1.943 & 18132400 & Down & $8 p 22$ \\
\hline ASAHI & AA664I55 & -2.384 & 18234223 & Down & $8 p 22$ \\
\hline SCAM-I & AA700222 & -4.063 & 22724596 & Down & $8 p 22$ \\
\hline TNFRSFIOB & AA453410 & -2.201 & 23264878 & Down & $8 p 21$ \\
\hline STCI & AAI2656I & -2.717 & 24085387 & Down & $8 p 21$ \\
\hline FLJ25804 & AA678348 & 2.532 & 25792008 & $U_{p}$ & $8 p 21$ \\
\hline ESTs & N5III7 & -3.448 & 27265764 & Down & $8 p 21$ \\
\hline ESTs & H95956 & 2.756 & 29620387 & $U_{p}$ & $8 p 21$ \\
\hline DUSP4 & AA444049 & -2.003 & 29960552 & Down & $8 p 21$ \\
\hline RBPMS & $R 66067$ & -2.823 & 30220588 & Down & $8 p 21$ \\
\hline RBPMS & W67323 & -2.87 I & 30870731 & Down & $8 p 21$ \\
\hline PPP2CB & AA490696 & -2.129 & 31553844 & Down & $8 p 21$ \\
\hline GSR & AA777289 & -2.333 & 31641629 & Down & $8 p 21$ \\
\hline NRGI & $\mathrm{H} 24357$ & -1.848 & 33227982 & Down & $8 p 12$ \\
\hline TEM5 & AA044447 & -3.954 & 36112103 & Down & $8 p 12$ \\
\hline STAR & AA679454 & -2.335 & $3887 \mid 582$ & Down & $8 p 12$ \\
\hline C8orf4 & HI6793 & -2.726 & 40119560 & Down & $8 p 12$ \\
\hline POLB & R44427 & -2.926 & 42052597 & Down & $8 p 12$ \\
\hline IKBKB & N944I 2 & -1.969 & 42092090 & Down & $8 p 12$ \\
\hline PLAT & R38933 & -2.076 & 42273247 & Down & $8 p 12$ \\
\hline ESTs & R070I2 & $2.48 \mathrm{I}$ & 48374593 & $U_{p}$ & $8 \mathrm{pll}$ \\
\hline
\end{tabular}

deletions and five normal human prostate tissues diploid for $8 p$ as controls.

In this study, we hypothesized that gene expression levels would be reduced or ablated in tumors deleted, or haploinsufficient, for one copy of $8 \mathrm{p}$. Consistent with this hypothesis, 28/33 (85\%) of the differentially expressed genes that mapped to $8 \mathrm{p}$ were down-regulated in the prostate tumor xenografts compared to normal prostate tissues.

Two of the genes identified as transcriptionally down-regulated in xenografts deleted for $8 \mathrm{p}$ were TEM5 and RBP-MS. TEM5 maps to 8p12 and encodes a seven-pass transmembrane protein (Carson-Walter et al., 2001). Although the protein was originally described as exclusively expressed on the surface of tumor endothelial cells, our studies show that the TEM5 gene transcript was clearly expressed in normal, but not malignant, prostate epithelium. $R B P-M S$ maps to $8 \mathrm{p} 21$ at the distal boundary of the $8 \mathrm{p} 21-8 \mathrm{p} 12$ deletion breakpoint previously observed in human prostate tumors (Shimamoto et al., 1996; Prasad et al., 1998). The $R B P-M S$ gene encodes an RNA-binding protein with complex alternative splicing patterns, resulting in at least 12 different transcripts (Shimamoto et al., 1996). The original description of this gene also showed strong expression of $R B P-M S$ transcripts in the human prostate, as well as the heart, small and large intestines, and ovaries (Shimamoto et al., 1996). The more conserved N-terminal region contains RNA-binding sequences homologous to similar motifs in the Drosophila couch potato gene transcript, whereas the $\mathrm{COOH}$-terminal region is highly divergent between the splice variants. Recent studies demonstrated that couch potato is involved in peripheral nervous system development, but is also highly expressed in the ring gland, the major Drosophila endocrine organ, throughout development (Harvie et al., 1998). The presence of RNA-binding motifs suggests that the RBP-MS 

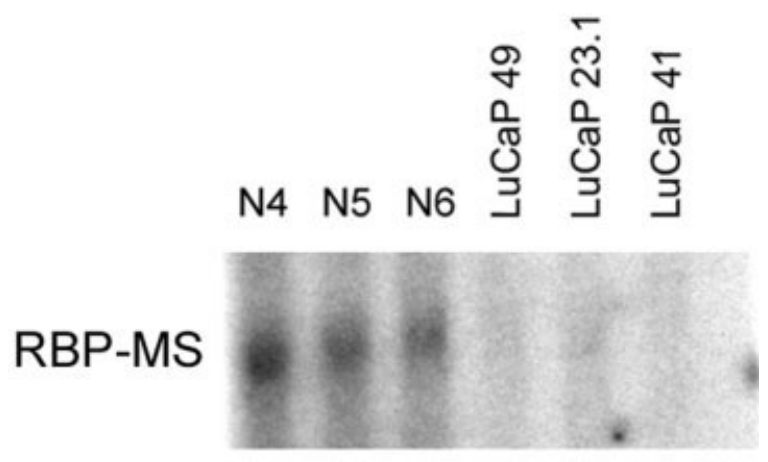

TEM5

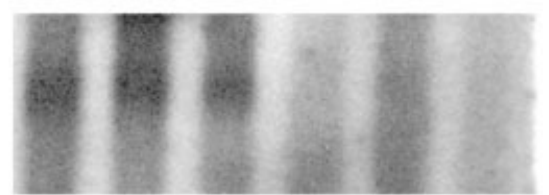

\section{GAPDH}

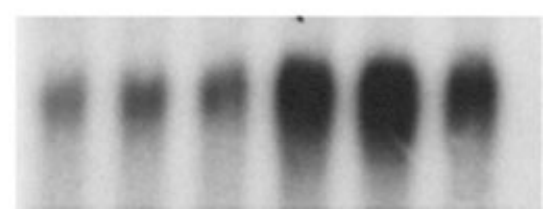

Figure 2. Northern blot validation of cDNA microarray data. Total RNA from normal specimens N4, N5, and N6 and from tumor specimens LuCaP 49, 23.I, and 4I were electrophoresed and blotted as described in the text. The Northern blot filter was sequentially hybridized to radiolabeled probes for RBP-MS, TEM5, and GAPDH (as a loading control). The normal prostate specimens demonstrated abundant expression of all three genes. However, RBP-MS and TEM5 were not expressed in LuCaPs 49, 23.I, and 4I, whereas GAPDH was clearly expressed in all three prostate tumor xenograft tissues. These results are consistent with the cDNA microarray results and demonstrate ablation of TEM5 and RBP-MS gene expression in prostate tumor xenografts deleted for one copy of $8 p$.

protein may be involved in RNA processing, transport, stabilization, or translation. Moreover, its high expression levels in the major endocrine organs of Drosophila (ring gland) and humans (ovaries, prostate) suggests that the RBP-MS protein may play a major role in these processes during sexual maturity and/or reproduction.

Several recent studies have suggested that haploinsufficiency for specific genes is associated with the initiation or progression of sporadic tumors in mice and humans. In particular, haploinsufficiency attributed to chromosomal deletion rather than base sequence mutation associated with tumorigenesis and progression has been described for the PTEN gene in mouse prostate tumors, the p27KIP1 gene in human acute lymphocytic leukemia, and the KLF5 transcription factor gene in human breast tumors (Komuro et al., 1999; Kwabi-Addo et al., 2001; Chen et al., 2002). Taken together, these data suggest that the transcriptional down-regulation of genes associated with deletion-induced haploinsufficiency may help identify candidate tumor- suppressor genes in human cancers. In particular, our finding that haploinsufficiency and transcriptional down-regulation for genes mapping to $8 \mathrm{p}$ are largely coincident in human prostate tumors provides a powerful tool for the identification of tumor-suppressor genes associated with human prostate cancer initiation and progression.

\section{ACKNOWLEDGMENTS}

This work was supported, in part, by National Cancer Institute grants 5 R01 CA60948 and 5 P30 CA46592 (to J.A.M.), grant 5 P50 DK47656 from the George M. O'Brien Prostate Cancer Research Center of the University of Washington Department of Urology (to R.L.V.), and a grant from the Department of Veterans Affairs (to R.L.V.).

\section{REFERENCES}

Beheshti B, Karaskova J, Park PC, Squire JA, Beatty BG. 2000. Identification of a high frequency of chromosomal rearrangements in the centromeric regions of prostate cancer cell lines by sequential Giemsa banding and spectral karyotyping. Mol Diagn 5:23-32.

Bergerheim USR, Kunimi K, Collins VP, Ekman, P. 1993. Deletion mapping of chromosomes 8,10 , and 16 in human prostatic carcinoma. Genes Chromosomes Cancer 3:215-220.

Bova GS, Carter BS, Bussemakers JG, Emi M, Fujiwara Y, Kyprianou N, Jacobs SC, Robinson JC, Epstein JI, Walsh PC, Isaacs WB. 1993. Homozygous deletion and frequent allelic loss of chromosome $8 \mathrm{p} 22$ loci in human prostate cancer. Cancer Res 53:3869-3873.

Bova GS, MacGrogan D, Levy A, Pin SS, Bookstein R, Isaacs WB. 1996. Structure and methylation-associated silencing of a gene within a homozygously deleted region of human chromosome band 8p22. Genomics 35:46-54.

Carson-Walter EB, Watkins DN, Nanda A, Vogelstein B, Kinzler KW, St Croix B. 2001. Cell surface tumor endothelial markers are conserved in mice and humans. Cancer Res 61:6649-6655.

Chen C, Bhalala HV, Qiao H, Dong JT. 2002. A possible tumor suppressor role of the KLF5 transcription factor in human breast cancer. Oncogene 21:6567-6572.

Corey E, Quinn JE, Buhler KR, Nelson PS, Macoska JA, Vessella RL. 2002. LuCaP 35: a new prostate cancer xenograft with metastatic potential. Prostate (in press).

Eisen MB, Spellman PT, Brown PO, Botstein D. 1998. Cluster analysis and display of genome-wide expression patterns. Proc Natl Acad Sci USA 95:14863-14868.

Ellis WJ, Vessella RL, Buhler KR, Bladou F, True LD, Bigler SA, Curtis D, Lange PH. 1996. Characterization of a novel androgensensitive, prostate-specific antigen-producing prostatic carcinoma xenograft: LuCaP 23. Clin Cancer Res 2:1039-1048.

Harvie PD, Filippova M, Bryant PJ 1998. Genes expressed in the ring gland, the major endocrine organ of Drosophila melanogaster. Genetics 149:217-231.

Komuro H, Valentine MB, Rubnitz JE, Saito M, Raimondi SC, Carroll AJ, Yi T, Sherr CJ, Look AT. 1999. p27KIP1 deletions in childhood acute lymphoblastic leukemia. Neoplasia 1:253-261.

Kwabi-Addo B, Giri D, Schmidt K, Podsypanina K, Parsons R, Greenberg N, Ittmann M. 2001. Haploinsufficiency of the Pten tumor suppressor gene promotes prostate cancer progression. Proc Natl Acad Sci USA 98:11563-11568.

Laitinen S, Karhu R, Sawyers CL, Vessella RL, Visakorpi T. 2002. Chromosomal aberrations in prostate cancer xenografts detected by comparative genomic hybridization. Genes Chromosomes Cancer 35:66-73.

Linja MJ, Savinainen KJ, Saramaki OR, Tammela TL, Vessella RL, Visakorpi T. 2001. Amplification and overexpression of androgen receptor gene in hormone-refractory prostate cancer. Cancer Res 61:3550-3555.

MacGrogan D, Levy A, Bostwick D, Wagner M, Wells D, Bookstein R. 1994. Loss of chromosome arm 8p loci in prostate cancer: 
mapping by quantitative allelic imbalance. Genes Chromosomes Cancer 10:151-159.

Macoska JA, Trybus TM, Sakr WA, Wolf MC, Benson PD, Powell IJ, Pontes JE. 1994. Fluorescence in situ hybridization (FISH) analysis of $8 \mathrm{p}$ allelic loss and chromosome 8 instability in human prostate cancer. Cancer Res 54:3824-3830.

Macoska JA, Trybus TM, Benson PD, Sakr WA, Grignon DJ, Wojno KD, Pietruk T, Powell IJ. 1995. Evidence for three tumor suppressor gene loci on chromosome $8 \mathrm{p}$ in human prostate cancer. Cancer Res 55:5390-5395.

Prasad MA, Wojno KJ, Macoska JA. 1998. Homozygous and frequent deletion of proximal $8 \mathrm{p}$ sequences in human prostate cancers: identification of a potential tumor suppressor gene site. Genes Chromosomes Cancer 23:255-262.

Shedden KL. 2002a. Access at http://www.stat.lsa.umich.edu/ $\sim$ kshedden/Normalize/

Shedden KL. 2002b. Access at http://dot.ped.med.umich.edu:2000/ ourimage/microarrays/kerby norm.htm

Shimamoto A, Kitao S, Ichikawa K, Suzuki N, Yamabe Y, Imamura O, Tokutake Y, Satoh M, Matsumoto T, Kuromitsu J, Kataoka H, Sugawara K, Sugawara M, Sugimoto M, Goto M, Furuichi Y. 1996.

A unique human gene that spans over $230 \mathrm{~kb}$ in the human chromosome 8p11-12 and codes multiple family proteins sharing RNA-binding motifs. Proc Natl Acad Sci USA 93:10913-10917.

Trapman J, Sleddens HFBM, van der Weiden MM, Dinjens WNM, Konig JJ, Schroder FH, Faber PW, Bosman FT. 1994. Loss of heterozygosity of chromosome 8 microsatellite loci implicates a candidate tumor suppressor gene between the loci D8S87 and D8S133 in human prostate cancer. Cancer Res 54:6061-6064.

True LD, Buhler K, Quinn J, Williams E, Nelson PS, Clegg N, Macoska JA, Norwood T, Liu A, Ellis W, Lange P, Vessella R. 2002. A neuroendocrine/small cell prostate carcinoma xenograftLuCaP 49. Am J Pathol 161:705-715.

Tseng GC, Oh M-K, Rohlin L, Liao JC, Wong WH. 2001. Issues in cDNA microarray analysis: quality filtering, channel normalization, models of variation and assessment of gene effects. Nucleic Acids Res 29:2549-2557.

Tusher G, Tibshirani R, Chu G. 2001. Significance analysis of microarrays applied to the ionizing radiation response. Proc Natl Acad Sci USA 98:5116-5121.

Williams BJ, Jones E, Kozlowski JM, Vessella R, Brothman AR. 1997. Comparative genomic hybridization and molecular cytogenetic characterization of two prostate cancer xenografts. Genes Chromosomes Cancer 18:299-304. 